\title{
Effect of oestrogen during menopause on risk and age at onset of
} Alzheimer's disease

Ming-Xin Tang, Diane Jacobs, Yaakov Stern, Karen Marder, Peter Schofield, Barry Gurland, Howard Andrews,

Richard Mayeux

\section{Summary}

Background Oestrogen use by postmenopausal women has many health benefits, but findings on the effect of oestrogen in Alzheimer's disease are conflicting. Oestrogen promotes the growth and survival of cholinergic neurons and could decrease cerebral amyloid deposition, both of which may delay the onset or prevent Alzheimer's disease. To investigate whether use of oestrogen during the postmenopausal period affects the risk of Alzheimer's disease, we studied 1124 elderly women who were initially free of Alzheimer's disease, Parkinson's disease, and stroke, and who were taking part in a longitudinal study of ageing and health in a New York City community.

Methods Relative risks and age-at-onset distributions were calculated from simple and adjusted Cox proportional hazards models. Standard annual clinical assessments and criterion-based diagnoses were used in follow-up (range 1-5 years).

Findings Overall, 156 (12.5\%) women reported taking oestrogen after onset of menopause. The age at onset of Alzheimer's disease was significantly later in women who had taken oestrogen than in those who did not and the relative risk of the disease was significantly reduced (9/ 156 [5.8\%] oestrogen users vs 158/ 968 [16.3\%] nonusers; $0.40[95 \% \mathrm{Cl} \quad 0.22-0.85], p<0.01)$, even after adjustment for differences in education, ethnic origin, and apolipoprotein-E genotype. Women who had used oestrogen for longer than 1 year had a greater reduction in risk; none of 23 women who were taking oestrogen at study enrolment has developed Alzheimer's disease.

Interpretation Oestrogen use in postmenopausal women may delay the onset and decrease the risk of Alzheimer's disease. Prospective studies are needed to establish the dose and duration of oestrogen required to provide this benefit and to assess its safety in elderly postmenopausal women.

Lancet 1996; 348: 429-32

See Commentary page 420

Gertrude H Sergievsky Center ( $M-X$ Tang PhD, D J acobs PhD, Y Stern PhD, K M arder MPH, P Schofield MD, R M ayeux MD); Taub Center for Alzheimer's Disease Research (D Jacobs, Y Stern, K Marder, H Andrews PhD, R M ayeux); Departments of Neurology (M-X Tang, D Jacobs, Y Stern, K Marder, P Schofield, R Mayeux) and Psychiatry ( $Y$ Stern, $B$ Gurland $M D, R$ Mayeux) and Division of Epidemiology (R Mayeux) (School of Public Health): Stroud Center for the Study of Quality of Life, Columbia University, College of Physicians and Surgeons (B Gurland); and Division of Statistics, New York State Psychiatric Institute (H Andrews), New York, USA

Correspondence to: Dr Richard Mayeux, Gertrude H Sergievsky Center, 630 West 168th Street, Columbia University, New York, NY 10032, USA

\section{Introduction}

U se of oestrogen by postmenopausal women has many health benefits. ${ }^{1,2} \mathrm{O}$ estrogen has been used as a treatment ${ }^{3,4}$ for Alzheimer's disease, which affects a substantial proportion of elderly women. ${ }^{5}$ One study reported that oestrogen use was associated with a lower risk of mortality related to Alzheimer's disease, ${ }^{6}$ although a subsequent case-control study did not confirm this association. ${ }^{7}$ Oestrogen promotes the growth of cholinergic neurons, $, 8,9$ stimulates the secretase metabolism of the amyloid precursor protein ${ }^{10}$ and may interact with apolipoprotein E. ${ }^{11}$ All these factors could affect the risk of Alzheimer's disease.

We examined the effect of a history of oestrogen use on the development of Alzheimer's disease among elderly women living in $\mathrm{New}$ York. Our hypothesis was that oestrogen use might lower the risk of incident Alzheimer's disease.

\section{Methods}

1282 non-demented elderly women were identified in a community-based study of ageing in northern $\mathrm{M}$ anhattan, $\mathrm{N}$ ew Y ork $\mathrm{C}$ ity. The $\mathrm{H}$ ealth $\mathrm{C}$ are Financing Administration provided access to a random sample of $M$ edicare recipients in the community. Additional potential participants were consecutively identified from records at senior centres and elderly housing sites in the same community. We wrote to potential participants identified by either method explaining that they had been selected to take part in a study of ageing. Participation rates were $77 \%$ at the senior centres and housing sites and $72 \%$ in the Medicare sample; these rates did not differ by ethnic origin. Each participant underwent a 90 min face-to-face interview then a standard assessment, which included a medical history, physical and neurological examination, and a brief (about $1 \mathrm{~h}$ ) battery of neuropsychological tests. ${ }^{12,13}$ The criteria for eligibility were: no evidence of cognitive impairment on detailed psychometric assessment at the initial interview; no history of stroke or Parkinson's disease; and at least one subsequent annual follow-up assessment.

Information about oestrogen use was available for 1227 $(95 \cdot 7 \%)$ women. From this group we excluded $52(4 \cdot 2 \%)$ women with Parkinson's disease, $45(3.7 \%)$ with stroke, and six (0.5\%) with both disorders. Thus, we restricted the analysis to 1124 women-352 (31\%) women identified at the senior centres and housing sites and $772(69 \%)$ from the M edicare sample. The Columbia University Institutional Review Board reviewed and approved this project.

A standard history of oral oestrogen use was obtained from all women at study entry by a trained interviewer as part of the riskfactor questionnaire. The test-retest reliability of the overall questionnaire had been previously established. ${ }^{14}$ Q uestions about oestrogen use had good test-retest reliability $(\kappa=0.65)$. If a woman had ever taken oestrogen, she was asked the ages at which she began and stopped. She was asked how old she was at the onset of the menopause and whether it occurred naturally or as a result of surgery. We asked the women to name the type of oestrogen preparation they used but not the dosages.

For diagnosis of dementia, medical records and imaging studies were used, as well as data from the initial and follow-up 


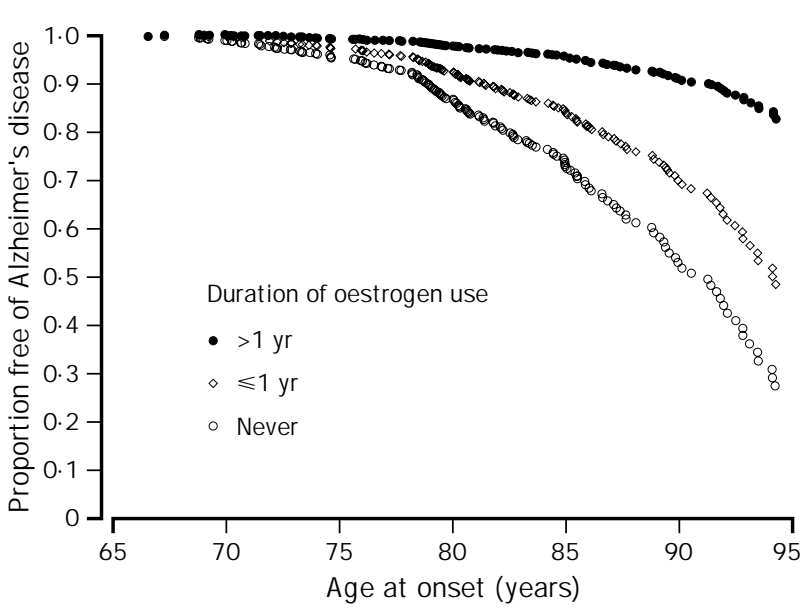

Figure: Survival analysis plot of distribution by age of proportion of individuals remaining unaffected according to duration of oestrogen use

Duration of use $>1$ year, average $=13.6$ years; $\leqslant 1$ year, average $=4$ months. Women classified as unknown duration of use (table 2 ) included in reference group.

inclusion in the analysis, $181(16 \cdot 1 \%)$ had no additional follow-up information. These women were similar to the 943 with additional follow-up in age (mean 75.4 [SD 7.8] vs $74 \cdot 2[6 \cdot 8]$ years), education $(9 \cdot 3[4 \cdot 7]$ vs $9 \cdot 2[4 \cdot 6]$ years), ethnic origin (African-American 62 [34.3\%] vs other $338[35 \cdot 8 \%])$, and oestrogen use (22 [12.5\%] vs 134 $[14 \cdot 2 \%])$. F or women with additional follow-up, the duration did not differ significantly by history of oestrogen use or by the devel opment of Alzheimer's disease $(p=0 \cdot 7)$.

A POE genotypes were available for $604(53 \cdot 7 \%)$ of the 1124 women. The risk of incident Alzheimer's disease was higher for women with APOE $\varepsilon 4$ than for those with other genotypes $(\varepsilon 4 / \varepsilon 4 \quad 3.9$ [1.5-9.8]; one $\varepsilon 4$ allele $1 \cdot 2[0 \cdot 7-1 \cdot 6])$. N one of the nine APOE $\varepsilon 4$ homozygous women had taken oestrogen (three cases, six controls). The relative risk for Alzheimer's disease associated with oestrogen use among APOE\&4 heterozygous women was reduced $(0.13$ [0.02-0.95]) as was that among women with other APOE genotypes $(0 \cdot 4[0 \cdot 2-0 \cdot 9])$.

The estimated annual incidence rate of Alzheimer's disease was $2 \cdot 7 \%$ among women who took oestrogen compared with $8.4 \%$ among those who did not take oestrogen. The overall incidence rate ratio was 0.4 $(0 \cdot 2-0 \cdot 7)$, similar to that estimated in the Cox proportional hazards model. 68 patients ( $41 \%$ of the 167 patients) showed mild impairment of cognitive function but met criteria for inclusion. We repeated the analysis after excluding these mildly impaired women to estimate the relative risk of more advanced disease $(n=99)$, but the results of the Cox model were similar (relative risk $[0.25-0.9], p=0.04)$ as was the incidence rate ratio $(0.24$ [0.09-0.69]; incidence rate oestrogen $1.2 \%$ vs no oestrogen $5.4 \%$ ). The annual incidence rates are within the ranges reported previously in East Boston. ${ }^{20}$

\section{Discussion}

These results suggest that a history of oestrogen use during the postmenopausal period significantly delays the onset of Alzheimer's disease and lowers the risk of disease. The duration of oestrogen use seems to be important in risk reduction because women with a history of long-term use had the lowest risk. Our study differs from previous investigations of Alzheimer's disease ${ }^{6,7}$ in that all women were interviewed about the use of oestrogen and examined before the onset of disease.

Paganini- $\mathrm{H}$ ill and $\mathrm{H}$ enderson ${ }^{6}$ reported a reduction with oestrogen use in mortality related to Alzheimer's disease in a nested case-control study; 13979 (61\%) participants completed a health survey by mail, but follow-up was limited to health records and death certificates. L onger periods of oestrogen use and younger age at menarche were also associated with lower mortality.

G raves et $\mathrm{al}^{21}$ found no difference between patients with Alzheimer's disease and controls in the frequency of oestrogen replacement, though sex distribution was not described. B renner and colleagues ${ }^{7}$ found no evidence that oestrogen replacement therapy affected the risk of Alzheimer's disease; though no significant association was observed, the odds ratio for oral oestrogen use associated with Alzheimer's disease was less than one. That study ${ }^{7}$ had sufficient power to detect a reduction in risk similar to that in our study but the study design ${ }^{3}$ may explain why the outcomes differ. Brenner and colleagues' main comparison was of the odds that patients with Alzheimer's disease used oestrogen and the odds that controls used oestrogen. By contrast, we classified women on the basis of a history of oestrogen use and compared the cumulative risk that Alzheimer's disease would develop among oestrogen-users and never-users. O ur results (figure) show that oestrogen use does not prevent Alzheimer's disease, but that it seems to delay the onset of the disease. The case-control design used by B renner et $\mathrm{al}^{7}$ would not allow examination of differences in the age-at-onset distribution.

T oran-Allerand and colleagues ${ }^{8}$ identified colocalisation of oestrogen-receptor binding sites with the mRNA for nerve growth factors and their receptors in developing neurons of rodent basal forebrain. ${ }^{22}$ The degeneration of these regions in Alzheimer's disease may cause the loss of memory and other cognitive functions. Their findings imply that oestrogen and nerve growth factors influence synthesis and release of nerve growth factors or alternatively promote survival, differentiation, regeneration, and plasticity. In a study of rats that had undergone oophorectomy, those treated with $17 \beta$ oestradiol did better on a memory task than those deprived of oestrogen; these animals also showed preservation of neurons in the basal forebrain as well as a return to near-normal concentrations of $\mathrm{mRNA}$ for nerve growth factors. ${ }^{9,23,24}$

Oestrogen protects hippocampal neurons in culture exposed to excitotoxins, oxidative stress, or amyloid $\beta . .^{25}$ Cells cultured with $17 \beta$-oestradiol accumulate a soluble form of the amyloid precursor protein by enhancing the amount or activity of $\alpha$-secretase. ${ }^{10}$ An exogenous source of oestrogen in postmenopausal women, even for a limited time, might foster the survival of neurons and limit the amount of amyloid $\beta$ deposition, thus delaying the onset of overt manifestations of Alzheimer's disease.

The association between APOE\&4 and Alzheimer's disease has been extensively investigated, ${ }^{26,27}$ and our results are similar to other population estimates. ${ }^{28}$ O estrogen use was associated with a reduction in the risk of Alzheimer's disease among women heterozygous for $\varepsilon 4$ and among women with other APOE genotypes, but we were unable to assess the effect of oestrogen among women homozygous for $\varepsilon 4$.

This study has limitations because the design was observational. Oestrogen use was assessed by history. O estrogen use was less common among A frican-American 
women and more likely among better-educated women. Although we adjusted for some of these factors in our analyses, we cannot exclude the possibility that oestrogen use reflects a lifestyle characteristic or an as yet unidentified exposure or bias that accounts for the effect observed. We believe that a prospective trial of oestrogen in perimenopausal women to delay the onset of Alzheimer's disease is justified, once more data on the safety, dosage, and duration of oestrogen treatment required become available.

We thank D avid Wilder and Rafael L antigua (Stroud Center for the Study of Quality of L ife and Center for G eriatrics and Gerontology at Columbia U niversity) for their help in the design and conduct of the registry and $M$ edicare survey; John Shinin, $M$ aria $G$ onzales, $H$ arold Brown, and Roseann C osta for technical assistance; interview team from the Sergievsky C enter and the $\mathrm{C}$ enter for $\mathrm{G}$ eriatrics and G erontology at Columbia U niversity; and $\mathrm{N}$ icole Schupf, W ei-Y en T sai, Allen $\mathrm{H}$ auser, and $\mathrm{D}$ ominique T oran-Allerand for review of this work.

This study was supported by federal grants A G 07232, A G 10963 A G 08702, and RR00645 and the Charles S Robertson M emorial G ift for Alzheimer's disease research from the Banbury F und. M-XT is supported by a F aculty Scholar A ward (95-045) from the Alzheimer's D isease and Related Disorders Association.

\section{References}

1 Bush T L, Cowan LD, Barrett-C onnor E, et al. Estrogen use and allcause mortality: preliminary results from the $L$ ipid Research $C$ linics Program Follow-U p Study. J A M A 1983; 249: 903-06.

2 Ettinger $B$, F riedman GD, Bush $T$, Q uesenberry $C P$. Reduced mortality associated with long-term postmenopausal estrogen therapy O bstet G ynecol 1996; 87: 6-12.

3 Fillit $\mathrm{H}$, Weinreb $\mathrm{H}, \mathrm{C}$ holst $\mathrm{I}$, et al. Observations in a preliminary open trial of estradiol therapy for senile dementia-Alzheimer's type. Psychoneuroendocrinology 1986; 11: 337-45.

4 Henderson VW, Paganini-H ill A, Emanuel CK, D unn M E, Buckwalter JG. Estrogen replacement therapy in older women: comparisons between Alzheimer's disease cases and nondemented control subjects. A rch N eurol 1994; 51: 896-900.

5 Rocca WA, Amaducci LA, Schoenberg BS. E pidemiology of clinically diagnosed Alzheimer's disease. A nn N eurol 1986; 19: 415-24.

6 Paganini-H ill A, Henderson VW. Estrogen deficiency and risk of Alzheimer's disease in women. A m J E pidemiol 1994; 140: 256-61.

7 Brenner DE, K ukull WA, Stergachis A, et al. Postmenopausal estrogen replacement therapy and the risk of Alzheimer's disease: a populationbased case-control study. A m J E pidemiol 1994; 140: 262-67.

8 T oran-Allerand CD, M iranda RC, Bentham WD, et al. Estrogen receptors colocalize with low affinity nerve growth factor receptors in cholinergic neurons of the basal forebrain. Proc $\mathrm{N}$ atl A cad Sci U SA 1992; 89: 4668-72.

9 Simpkins JW, Singh M, Bishop J. The potential role for estrogen replacement therapy in the treatment of the cognitive decline and neurodegeneration associated with Alzheimer's disease. N eurobiol A ging 1994; 15 (suppl 2): S195-97.

10 Jaffe AB, T oran-Allerand CD, G reengard P, G andy SE. Estrogen regulates metabolism of Alzheimer's amyloid beta precursor protein.
J Biol Chem 1994; 269: 13065-68.

$11 \mathrm{H}$ onjo $\mathrm{H}$, T anaka K, K ashiwagi T, et al. Senile dementia-Alzheimer's type and estrogen. H ormone M etab R es 1995; 27: 204-07.

12 Stern $Y$, Andrews H, Pittman J, et al. D iagnosis of dementia in a heterogeneous population: development of a neuropsychological paradigm and quantified correction for educated. A rch N eurol 1992; 49: 453-60.

13 Pittman J, Andrews $\mathrm{H}, \mathrm{T}$ atemichi $\mathrm{T}$, et al $\mathrm{D}$ iagnosis of dementia in a heterogeneous population: a comparison of paradigm-based diagnosis and physician's diagnosis. A rch N eurol 1992; 49: 461-67.

14 M ayeux R, Ottman R, T ang M - X, et al. G enetic susceptibility and head injury as risk factors for Alzheimer's disease among communitydwelling elderly persons and the first-degree relatives. A nn N eurol 1993; 33: 494-501.

15 American Psychiatric Association Diagnostic and statistical manual of mental disorders, 3rd edn, revised. Washington, D C : American Psychiatric Association, 1987: 205-24.

16 M CK hann G, D rachman D, Folstein M, K atzman R, Price D, Stadland $E$. C linical diagnosis of Alzheimer's disease: report of the N IN CDS-ADRDA Work Group under the auspices of the D epartment of $\mathrm{H}$ ealth and $\mathrm{H}$ uman Services T ask F orce on Alzheimer's disease. N eurology 1984; 34: 939-44.

17 Hixson J, Vernier D. Restriction isotyping of human apolipoprotein E by gene amplification and cleavage with H hAl. J Lipid Res 1991; 31: 545-48.

18 M aestre G, Ottman R, Stern $Y$, et al. A polipoprotein-E and Alzheimer's disease: ethnic variation in genotypic risks. A nn N eurol 1995; 37: 254-59.

19 Collet $D$. M odelling survival data in medical research. L ondon: Chapman and $\mathrm{H}$ all, 1994: 153-54.

$20 \mathrm{H}$ erbert LE, Scherr PA, Beckett LA, et al. Age-specific incidence of Alzheimer's disease in a community population. J A M A 1995; 273: 1354-59.

21 G raves AB, White E, K oepsell T D, et al. A case-control study of Alzheimer's disease. A nn N eurol 1990; 28: 766-74.

$22 \mathrm{M}$ iranda RC, Sohrabji F, T oran-Allerand CD. Estrogen target neurons co-localize the $\mathrm{mRN}$ As for the neutrophins and their receptors during development: a basis for the interactions of estrogen and the neurotrophins. M ol C ell N eurosci 1993; 4: 510-25.

23 Singh M, M eyer EM . Simpkins JW. The effect of ovariectomy and estradiol replacement on brain-derived neurotrophic factor messenge ribonucleic acid expression in cortical and hippocampal brain regions of female Sprague-D awley rats. Endocrinology 1995; 136: 2320-24.

24 Singh M, M eyer EM, H uang F S, M illard WJ, Simpkins JW. $O$ variectomy reduces $C h A T$ activity and NGF mRNA levels in the frontal cortex and hippocampus of the female Sprague D awley rat. A bstr Soc N eurosci 1993; 19: 1254

25 G oodman $Y$, Bruce AJ, C heng B, M attson M P. Estrogens attenuate and corticosterone exacerbates excitotoxicity, oxidative injury and amyloid $\beta$-peptide toxicity of hippocampal neurons. J N eurochem 1996; 66: $1836-44$

26 Saunders AM, Strittmatter WJ, Schmechel D, et al. Association of apolipoprotein $\mathrm{E}$ allele $\mathrm{e} 4$ with late-onset familial and sporadic Alzheimer's disease. N eurology 1993; 43: 1467-72.

27 Roses AD, Strittmatter WJ, Pericak-Vance M A, Corder EH, Saunders AM, Schmechel DE. Clinical application of apolipoprotein E genotyping to Alzheimer's disease. L ancet 1994; 343: 1564-65.

$28 \mathrm{H}$ enderson AS, Easteal S, Jorm AF, et al. A polipoprotein E allele $\varepsilon 4$ dementia, and cognitive decline in a population sample. L ancet 1995, 346: 1387-90. 